\title{
A Shock-Refracted Acoustic Wave Model for Screech Amplitude in Supersonic Jets
}

\author{
M. Kandula \\ Sierra Lobo Inc., John F. Kennedy Space Center, FL, USA
}

A physical model is proposed for the estimation of the screech amplitude in underexpanded supersonic jets. The model is based on the hypothesis that the interaction of a plane acoustic wave with stationary shock waves provides amplification of the transmitted acoustic wave upon traversing the shock. Powell's discrete source model for screech incorporating a stationary array of acoustic monopoles is extended to accommodate variable source strength. The proposed model reveals that the acoustic sources are of increasing strength with downstream distance. It is shown that the screech amplitude increases with the fully expanded jet Mach number. Comparisons of predicted screech amplitude with available test data show satisfactory agreement. The effect of variable source strength on the directivity of the fundamental (first harmonic, lowest frequency mode) and the second harmonic (overtone) is found to be unimportant with regard to the principal lobe (main or major lobe) of considerable relative strength, and is appreciable only in the secondary or minor lobes (of relatively weaker strength).

'Sr. Principal Investigator, Associate Fellow AIAA. 


\section{Introduction}

Supersonic jet screech constitutes an important technological challenge in the theory of jet noise. Screech refers to high-amplitude discrete tones superposed on the otherwise broadband acoustic spectrum observed in imperfectly expanded supersonic jets (Fig. 1). The shock noise produced by imperfectly expanded (choked) jets is very complex, and consists of two separate components, namely broadband shock noise (arising from shock-turbulence interaction) and screech tones. This shock noise is in addition to the broadband turbulent mixing noise in the jet [1-3]. In the nearfield, the very high intensity of these screech tones (as high as 170 to $180 \mathrm{~dB}$ ) with a highly directional character with significant upstream propagating component can induce fatigue and cause serious structural damage and failure of aerodynamic vehicles in flight. A fundamental understanding of jet screech amplitude is thus requisite to the design of a new generation of rocket engines [4-6], turbo-jet aircraft engines, and to a number of other flow circumstances such as jet impingement and cavity resonance involving feedback cycles.

Owing to pressure mismatch (nozzle exit pressure exceeds the ambient pressure), underexpanded supersonic jet structures manifest themselves in shock-cell structures involving normal/oblique shocks and regions of expansion (Fig. 2). Under certain conditions, a Mach disc is also formed. These shock-expansion units interact with instability waves, vortices, turbulence, and other stream disturbances in the viscous shear layer that surrounds the inviscid region.

Powell [7-9] first identified the mechanism of supersonic jet screech in terms of a resonant feedback loop or cycle that is self-sustaining and consists of the following key processes (Fig. 2): downstream passage of flow disturbances in the jet shear layer initiated near the nozzle lip region (where the relatively thin shear layer is susceptible to instability); interaction of these stream disturbances with the nearly periodic and stationary oblique shock-cell structure of the jet 
resulting in their amplification, with the ultimate generation and emission of intense acoustic waves or energy; upstream propagation of the acoustic waves immediately outside the jet shear layer (acoustic feedback); excitation and maintenance of stream disturbances in the vicinity of the nozzle lip by the upstream propagating acoustic waves (so-called receptivity), which then propagate downstream, thus closing the feedback cycle without any external interference. Experimental data, such as flow visualization measurements by Kaji \& Nishijima [10], suggest that the shock-noise is most intense somewhere between the third and fourth shock-cell structures. For a detailed discussion on screech, Seiner [11] may be consulted.

Powell's theory [7] of stationary array of discrete monopole sources distributed through the shock-cells provided directivity patterns of screech that agree with measurements, as reported by Norum [12] for unheated jets. It also furnished a framework for the estimation of screech frequency based on shock-cell spacing. Fisher \& Morfey [13] and Tam et al. [14] provided expressions for the prediction of screech frequency over a wide range of fully expanded jet Mach number $M_{j}$ and jet total temperature $T_{0}$. Tam's expression for the screech is predicated on the so-called weakest-link theory, according to which the feedback acoustic waves represent the weakest link and control the screech frequency. Massey \& Ahuja [15] expanded on Tam's formulation and provided expressions for screech frequency for hot jets with different screech modes. The screech mode changes from axisymmetric to helical and flapping modes as the Mach number $M_{j}$ increases.

On the basis of Powell's model of stationary point sources, Harper-Bourne and Fisher [16] experimentally and theoretically treated broadband shock noise (radiated to the farfield) by considering shock-turbulence interaction. Harper-Bourne and Fisher considered spatial coherence of the disturbance field to account for the broadband sound radiation to the farfield. 
Generally speaking, the intensity of broadband shock-associated noise is more prevalent in the forward arc, and is a function only of the pressure ratio. A stochastic model for broadband shock noise was reported by Tam [17] who considered the nonlinear interaction between jet turbulence and stationary shock-cell system. Shock-turbulence interaction (shear layer and an oblique compression wave) was numerically investigated by Lui \& Lele [18] including the dynamic motion of the shock during interaction with shear layer vortices.

With regard to the screech process, our current understanding of the highly nonlinear flow dynamics and of the rate of amplification of stream disturbances is rather incomplete. Whereas screech frequency is controlled by the feedback acoustic waves, the screech intensity is governed primarily by the characteristics of the downstream propagating flow disturbances and their interaction with the shock-cell structures. Several detailed measurements $[10,12,15,19-23]$ and numerical viscous simulations [10, 24-29] have been reported and served to throw light on the subject. The experimental description of A-D mode switch $\left(A_{1}, A_{2}, B, C, D\right)$ according to the jet operating parameters represents a notable step [12]. Despite the theoretical advances in screech frequency predictions, directivity character, modulations of instability waves by shocks [30-31] and unsteady shock motions and their role in noise generation, screech amplitude predictions remain elusive [32-33]. Owing to strong nonlinearity of the feedback loop, even an empirical formula for screech intensity is unavailable [24].

The preponderating questions concerning the interaction of shock waves with stream disturbances and the excitation of disturbances by upstream-traveling acoustic waves largely remain unanswered. The purpose of the present work is to investigate the amplitude of screech based on a physical model for the interaction of stream disturbances (primarily regarded as 
finite-amplitude acoustic waves) with shock waves. This paper is primarily based on the author's recent work [6].

\section{Proposed Physical Model}

\section{A. Source Distribution}

The present model builds on Powell's conception of stationary discrete acoustic monopoles (Fig. 3). However, in the present context account is taken of the variable strength of the monopoles, as the flow disturbances are amplified on their passage through the shock-cell system. As with Harper-Bourne and Fisher [16] the acoustic sources are regarded to be distributed along the lip line at locations in the jet shear layer where shock reflections take place. It is assumed that the sources $S_{1}, S_{2}, S_{3}$ are equally spaced. It is also assumed that relative to the source $S_{2}$, the source $S_{1}$ leads in phase $\tau$ and $S_{3}$ lags in an equal amount of phase $\tau$.

The downstream-propagating stream disturbances near the supersonic side of the shear layer and the upstream-traveling acoustic disturbances on the subsonic outer edge of the shear layer form two key components of the feedback process. Attention is focused here on the amplification of downstream-traveling stream disturbances.

\section{B. Shock-Acoustic Wave Interaction}

\section{Transmission of an Acoustic Wave through a Normal Shock}

The proposed model for the screech amplitude is based on the doctrine that the downstreampropagating stream disturbances in the screech cycle are regarded as acoustic-like (nearly isentropic pressure fluctuations) and are of finite amplitude. The amplification of these disturbances during their passage is a consequence of the interaction between an acoustic wave (of finite amplitude) and a stationary shock wave. If the screech cycle is regarded as analogous to 
a thermodynamic cycle (with energy transfers occasioned during shock interaction and scattering at the nozzle lip), the acoustic waves form the working medium for the screech cycle. Thus, it is likely that the upstream-propagating acoustic waves and downstream-traveling acoustic waves constitute the screech cycle. The scattering of upstream-propagating acoustic waves by the nozzle lip ensures that this is so, even though some of the incoming acoustic energy is transmitted to the hydrodynamic disturbances or instability waves in the shear layer in the receptivity process.

Unsteady phase-averaged measurements of nearfield pressure fluctuations in a round jet at $M_{j}=1.19$ by Panda [21] indeed reveal that the downstream-propagating disturbances contain both hydrodynamic pulsations and acoustic waves, whereas upstream-propagating components are only acoustic [33].

When an acoustic wave (traversing with sound speed relative to the moving fluid) is incident upon the shock from ahead of it (Fig. 4), no reflected acoustic wave can arise because the flow ahead is supersonic, and the acoustic wave (longitudinal isentropic sound wave) is transmitted (refracted) downstream of the shock. At the same time, perturbations in entropy and vorticity (both are nonisentropic and nonacoustic; these isobaric, transverse waves are termed entropyvorticity waves after Carrier) are generated, which are transported along with the flow behind the shock [34-35]. On the other hand, when an acoustic wave is incident upon the shock from behind it, no disturbances can arise in the medium ahead of the shock. The acoustic waves are merely reflected, and the entropy and vorticity waves are generated behind the shock. Thus, the refraction of the incident acoustic wave is assured as long as the approach flow is supersonic. 
The main relationships developed here are based on transmission through normal shocks, although the shocks in the jet are not wholly normal but oblique. The Mach number normal to the shock $M_{1 n}$ is related to the approach Mach number $M_{1}$ by the relation

$$
M_{1 n}=M_{1} \sin \beta_{1}
$$

where $\beta_{1}$ represents the shock wave angle (angle between the approach velocity and the plane of the shock). However, it is believed that the relationships based on the normal-shock assumption provide an upper limit to the screech tone intensity.

The passage and linear interaction of plane disturbances (sound waves) with a shock wave upon normal incidence for an ideal gas was first treated by Blokhitsev [36] and Burgers [37]. When the perturbing waves are normally incident upon the shock, the transmission coefficient is expressed by [36-37]

$$
\frac{\delta p_{2}}{\delta p_{1}}=\frac{2 M_{1 n}^{4}+2(\gamma+1) M_{1 n}^{3}+(3 \gamma-1) M_{1 n}^{2}+1-\gamma}{(\gamma+1)\left(1+M_{1 n}^{2}+2 M_{2 n} M_{1 n}^{2}\right)}
$$

where $\delta p_{1}$ and $\delta p_{2}$ denote the strength of the incident and refracted acoustic waves, respectively, $M_{1 n}$ the normal Mach number of the flow upstream of the shock, $M_{2 n}$ the normal Mach number of the flow downstream of the shock, and $\gamma$ the specific heat ratio. The downstream Mach number is obtained from the Rankine-Hugoniot normal shock relation [38]

$$
M_{2 n}^{2}=\frac{M_{1 n}^{2}+2 /(\gamma-1)}{[2 \gamma /(\gamma-1)] M_{1 n}^{2}-1}
$$

Fig. 5 presents the variation of the pressure amplification $\delta p_{2} / \delta p_{1}$ as a function of incoming Mach number $M_{1}$. The pressure amplification is seen to rapidly grow as the upstream Mach 
number is increased. For large values of $M_{1}$, the pressure ratio varies as $M_{1}^{2}$. For oblique shocks $(\beta<90 \mathrm{deg})$, the pressure amplification is less than that for the normal shock.

The result of the linear shock-acoustic wave interaction theory has been shown to be in close agreement with the numerical nonlinear Euler simulations by Zang et a. [39] for incident angles within about $30 \mathrm{deg}$ of the critical angle (zero degree incident angle refers to normal incidence) for the acoustic as well as vorticity wave. Although linear theory is employed here for shockacoustic wave interaction, the successive amplification is considered nonlinear.

\section{Successive Amplification (Shock-Cell Interaction)}

Based on the general behavior of the Mach number decay for typical underexpanded jet conditions, the following distribution of the approach (or upstream) Mach number for each tip of the shock-expansion unit (shock-cell reflection occurring in the shear layer) may be considered as a rough approximation:

$$
M_{1 i}=M_{r}-\left(M_{r}-1 / \sin \beta_{1}\right)(i-1) /(m-1) \quad i=1,2, \ldots m
$$

where $M_{r}$ is the upstream Mach number for the first shock-cell, $M_{1 i}$ the incident Mach number in the $i$ th shock-cell, and $m$ the total number of active shock-cells under consideration. Thus, Eq. (2a) ensures that $M_{1 i} \approx M_{r}$ for the first shock-cell $(i=1)$, and $M_{1 i}=1 / \sin \beta_{1}$ for the last cell $(i=m)$. Based on the available data, the quantity $M_{r}$ is approximated as

$$
M_{r} \approx 1.4 M_{j}
$$


The quantity $M_{1 i}$ could be more accurately obtained by a direct calculation, using numerical methods. In the present work, the choice of Eq. (2a) for approximating $M_{1 i}$ is based on the consideration that it facilitates a simpler formulation of the model.

The fully expanded Mach number $M_{j}$ is related to the pressure ratio $p_{t} / p_{a}$ and the PrandtlGlauert parameter $\beta$ by

$$
M_{j}=\frac{2}{\gamma-1}\left[\left(\frac{p_{t}}{p_{a}}\right)^{(\gamma-1) / \gamma}-1\right]
$$

and

$$
\beta=\sqrt{M_{j}^{2}-1}
$$

with $p_{t}$ and $p_{a}$ denoting jet total pressure and the ambient pressure, respectively. The PrandtlGlauert parameter $\beta$ is thus related to the strength of the normal shock wave. The number of shock reflections for a convergent-divergent nozzle strongly depends on the nozzle design Mach number $M_{d}$ and the operating pressure ratio.

The relative source strength in each shock-cell can be determined from Eqs. (1) and (2). Eqs. (1a) and (2a) assert that there is successive amplification of the sound waves during their passage through the shock-cell system, with the highest amplification rate occasioned in the first shockcell. The overall (or total) amplification becomes

$$
\frac{\Delta p_{m}}{\Delta p_{i n}}=\left(\frac{\delta p_{1}}{\delta p_{i n}}\right)\left(\frac{\delta p_{2}}{\delta p_{1}}\right) \ldots\left(\frac{\delta p_{m}}{\delta p_{m-1}}\right)
$$

where $\Delta p_{\text {in }}$ refers to the disturbance level upstream of the first shock-cell in the vicinity of the nozzle exit. 


\section{Screech Character}

\section{A. Screech Amplitude}

The screech amplitude (so-called excess tone level) relative to the broadband spectrum $S P L_{S}$ is expressed as

$$
S P L_{s}=20 \log _{10}\left(\Delta p_{m} / \Delta p_{\text {in }}\right)
$$

where $\Delta p_{m} / \Delta p_{\text {in }}$ is determined from Eq. (3). Thus, Eqs. (1a) to (4) enable us to compute the excess (or relative) screech amplitude as a function of jet Mach number. The excess tone noise represents the difference between the screech amplitude and the broadband level (both shockinduced and turbulence-induced) at the screech frequency in a given spectrum [15].

The above theory does not display a separate effect of jet temperature on screech tone intensity. Data of Massey et al [15] suggest that the tone intensity reduces with an increase in temperature. According to the measurements of Massey and Ahuja [40] mode switching occurs at elevated jet temperature, thereby affecting screech intensity.

\section{B. Screech Directivity}

In the present formulation, an extension of Powell's treatment [7-9] is considered for the directivity of screech based on stationary point sources along a line; see Lord Rayleigh [41]. The farfield radiation is determined synthetically by combining these sources. With each source of strength of $4 \pi$ and $4 \pi H$ for the fundamental and the first harmonic respectively, the distribution of velocity potential for a point source is of the form

$$
\phi=\frac{1}{r} e^{i k(c t-r)}+\frac{H}{r} e^{i k(c t-r)}
$$


where $c$ denotes the sound speed, $r$ the radial distance, $t$ the time elapsed, and $k$ the wave number, which is related to the wavelength $\lambda$ of the feedback acoustic wave by

$$
\lambda=2 \pi / k
$$

Following Powell, we assume that the phases $\tau_{1}=\tau_{2}=\tau$. For small ratios of $s / r$ (where $s$ denotes the shock-cell spacing), the potential for the fundamental of a three-cell shock system (for example) can be expressed as

$$
\phi_{f}=\frac{\left(1+a_{2}+a_{3}\right)}{r} D_{f} \cos k\left(c t-r-\delta_{t}\right)
$$

The quantities $a_{2}$ and $a_{3}$ respectively refer to the relative strengths of the second and the third shock-cell with the strength of the first shock-cell taken as unity. The phasing $\delta_{t}$ between consecutive monopoles is determined by shock-cell spacing and disturbance convection Mach number $M_{c}[12]$.

The directivity $D_{f}$ can be expressed as

$$
D_{f}=\frac{1}{\left(1+a_{2}+a_{3}\right)}\left[a_{2}+\left(1+a_{3}\right) \cos k(c \tau-s \cos \theta)\right]
$$

with

$$
\tau=s / u_{c}=s /\left(c M_{c}\right)
$$

where $\theta$ denotes the angle from the downstream flow direction and $u_{c}$ and $M_{c}$ refer to convective velocity and convective Mach number of the disturbance, respectively. Eq. (8) can be recast as 


$$
D_{f}=\frac{1}{\left(1+a_{2}+a_{3}\right)}\left[a_{2}+\left(1+a_{3}\right) \cos \frac{2 \pi s}{\lambda M_{c}}\left(1-M_{c} \cos \theta\right)\right]
$$

Thus, the directionality of screech strongly depends on the shock cell spacing and the disturbance Mach number [7]. The quantity $\left(1-M_{c} \cos \theta\right)$ is a Doppler factor incorporating the variation in retarded time and source phasing [16]. An expression for the directivity of the harmonic $D_{h}$ is provided by Eq. (10) with $2 \pi$ replaced by $4 \pi$. In the special case of $a_{2}=a_{3}=1$, Eq. (10) reduces to that derived by Powell [7] for uniform source strength. Eq. (10) can be extended to four or more sources.

The shock-cell spacing $s$ is obtained from experimental data and is related to the pressure ratio parameter $\beta$ defined by

$$
s / d_{j}=f(\beta)
$$

For example, data of Harper-Bourne and Fisher [16] suggest that

$$
s / d_{j} \approx 1.25 \beta
$$

Experimental data [7] suggest that the shock-cell spacing is related to the feedback acoustic wave length as

$$
s / \lambda \approx 0.4
$$

where $\lambda$ is an integer.

Detailed measurements by Harper-Bourne [42] suggest that the shock-cell spacing $s$ is not uniform, but varies somewhat along the jet. A non-uniform shock-cell spacing, which may affect the directivity, is unaccounted for in the present theory. Experimental investigations of Massey et 
al. [15] also indicate that the effect of heating on the directivity of screech is largely unimportant. No direct effect of jet temperature on the directivity of screech is however evident from Eq. (10).

\section{Existing Relations for Screech Frequency}

Tam et al. [14] proposed for the screech frequency a semi-empirical expression of the form

$$
f d_{j} / u_{j}=f\left(M_{j}, \gamma, T_{0} / T_{a}\right)
$$

where $T_{a}$ represents the ambient temperature. The fully expanded jet diameter $d_{j}$ is related to the jet exit diameter and the nozzle design Mach number $M_{d}$ as

$$
d_{j} / d=f\left(M_{j}, M_{d}, \gamma\right)
$$

This formula agrees well with the data and accommodates the effect of jet temperature (hot and cold jets). Massey and Ahuja [40] provided separate expressions, similar in form to Eq. (12), for different screech modes depending on the Mach number range.

The screech frequency increases with temperature since at a fixed Mach number, the convective velocity $u_{c}$ of the instability wave increases with temperature [15]. The frequency is inversely proportional to the total time of travel in the screech cycle, $\left(T_{1}+T_{2}\right)$, where $T_{1}$ refers to the time for the downstream-propagating instability wave to traverse the shock-cell system starting from the nozzle exit, and $T_{2}$ the time elapsed for the upstream-propagating feedback acoustic wave to reach the nozzle lip region. Thus, as the temperature increases, the value of $T_{1}$ increases so that the frequency decreases. 


\section{Results and Discussion}

In all the results presented here, except for the screech amplitude, all the sound pressure levels (dB) are taken relative to $20 \mu \mathrm{Pa}$. The quoted levels are in $\mathrm{dB}$ linear (unweighted).

\section{A. Streamwise Distribution of Acoustic Source Strength}

The streamwise distribution of the acoustic source pressure, as predicted by the present model for the normal shock case ( $\beta_{1}=90 \mathrm{deg}$ ), is depicted in Fig. $6 \mathrm{a}$ for various Mach numbers. The successive amplification of the stream disturbances along the shock cells is evident, with the source strength increasing with the Mach number. The corresponding results for an oblique shock with $\beta_{1}=60 \mathrm{deg}$ are presented in Fig. $6 \mathrm{~b}$. The amplification rates for the oblique shock case are less than those for the normal shock case, as evident from Fig. 5.

A comparison of the predicted amplification rates (for $\beta_{1}=90 \mathrm{deg}$ and $\beta_{1}=60 \mathrm{deg}$ ) with the data of Kaji and Nishijima [10] for $M_{j}=1.64$ and of Panda et al. [19] for $M_{j}=1.19$ and 1.42 is illustrated in Fig. 6c. The data are deduced from the original measurements in order to provide a direct comparison. In this context, it would be instructive to briefly present the data in the original form.

The streamwise amplitude measurements by Kaji and Nishijima [10] for $M_{j}=1.64$ (Fig. 7a) suggest that the highest intensity is located in the shear layer of the third or the fourth shock cell, whereas inside the jet the acoustic intensity is low. Interestingly, the data reveal low-pressure dips (dimple spots) in the source strength. According to Kaji and Nishijima [10] these dips are believed to be generated by the interaction between sources. There is a possibility that they could also be due to the expansion regions in the flow. 
Detailed measurements by Panda et al. [19] for a circular jet over a wide range of Mach number $\left(M_{j}=1.19\right.$ to 1.51$)$ show similar trends for the axial distribution of source strength, with the peak values as a whole showing an increasing trend with $M_{j}$, ultimately approaching a level of saturation followed by a relatively rapid decline in the screech levels (Fig. 7b).

The foregoing data for the amplification rate are deduced here such that the relative source strength from the data at the first shock cell is taken as that given by the theory. Fig. 6c suggests that the proposed theory based on the normal shock for the acoustic source strength at $M_{j}=1.2$ is in close agreement with the data of Panda et al. [19] for all the shock cells. However, at Mach numbers of 1.4 and 1.6, the amplification corresponding to $\beta_{1}=60 \mathrm{deg}$ (oblique shock) agrees closer with the measurements than that corresponding to the normal shock.

Numerical simulations by Manning and Lele [26] for a single shear layer-compression wave interaction suggest that the radiated acoustic pressure amplitude approaches a saturation level at increased distances from the origin of the shear layer (Fig. 7c). The trends of the present model qualitatively agree with these results, although in the exponential region, the amplification rates appear to be comparatively high with respect to those in the present model. However, a direct quantitative comparison of this result with the present model appears difficult in view of the fact that a single compression wave is considered in the computation.

\section{B. Screech Amplitude}

Fig. 8 presents the variation of the excess screech amplitude as a function of $M_{j}$ as provided by the foregoing theory. Experimental data reported by various investigators $[10,40,43-46]$ are also displayed here in an effort to validate the physical model. The theory for the normal shock 
case $\left(\beta_{1}=90 \mathrm{deg}\right)$ suggests that the excess screech amplitude increases from about $17 \mathrm{~dB}$ at $M_{j}$ $=1.05$ to about $46 \mathrm{~dB}$ at $M_{j}=2.0$, with the slope of the curve slowly diminishing with increasing $M_{j}$. The predictions for $\beta_{1}=60 \mathrm{deg}$, addressing the sensitivity of the results to the shock wave angle, show about $7 \mathrm{~dB}$ reduction in the screech amplitude relative to the normal shock case. The theory seems to be in reasonable agreement with the data from various sources over a range of Mach number, with the normal shock providing the upper limit, and the oblique shock $\left(\beta_{1}=60 \mathrm{deg}\right)$ yielding the lower limit.

Measurements for absolute screech amplitude (which includes broadband noise) for a 5:1 aspect ratio rectangular nozzle obtained by Panda et al. [19] for a wide span of $M_{j}$ confirm the general character of the present theory (Fig. 9) in the sense that the screech amplitude increases with the jet Mach number until saturation. However, this report does not present the excess tonal noise for a direct (quantitative) comparison with the present calculations which provide only the excess screech magnitude. It is believed that the saturation (leveling) of the amplitude at high Mach number (say $M>1.4$ ), as indicated by the data, may be qualitatively explained to some extent if the shock-wave angle varies (decreases) with downstream distance. The relatively rapid decline in the amplitude at $M_{j}=1.7$ is perhaps related to the change in the screech mode.

It is generally believed that the screech tone noises are generated by the interaction between the growing instability waves (vortices) developed from the nozzle lip area and the shock cell structures. Recently large eddy simulation of jet screech by Berland et al. [29] provided evidence to the shock leakage theory proposed in Suzuki and Lele [47]. In the present model, only the acoustic waves (with finite amplitude), which is a minor part of the strong hydrodynamic process of vortex/shock cell interaction, are extracted, and the shock cells (shocks and expansions) are 
simplified to norma1/oblique shocks. Thus the physics described in the model is quite different from the physics of shock/instability wave interaction. In both the situations, the acoustic wave intensities somehow grow in an exponential manner before the saturation state. The ability of the present model to reasonably predict screech amplitude is perhaps connected with this circumstance. In the proposed model, it is thus important to adjust the constants (such as $M_{r}=1.4 M_{j}$ in eq. (2b), and the angle $\left.\beta_{1}\right)$ to match the experimental data.

In reality the strongest interaction usually occurs at the $3^{\text {rd }}-5^{\text {th }}$ shock cell, and the shock cells become highly deformed and are unsteady. The assumption in the model that these shock cells still have the same shape and size and steady is somewhat untenable.

Also as the acoustic waves are of finite amplitude, the linear theory may not strictly apply. Generally speaking, the accuracy of the linear theory appears questionable for weak shocks, strong disturbances, and incident angles close to the critical angle [39]. With regard to the incident waves of finite amplitude, numerical Euler simulations of Zong et al. [39] with amplitudes ranging from 0.01 to 0.5 suggest that the linear theory surprisingly remains reliable to extraordinarily large amplitudes.

The effect of screech mode on the screech intensity is beyond the scope of the present investigation. The dependence of screech intensity on jet temperature is also excluded from consideration in the present report. A detailed account of nozzle lip thickness is also not addressed here. 


\section{Screech Directivity}

Sample calculations of the directivity of screech for a typical value of $M_{j}=1.4$ for a threesource system are depicted in Figs. 10a and 10b, respectively, for the fundamental and the second harmonic. An effective value of $M_{c}=0.7$ is chosen as a representative value. Results for variable strength as obtained from Eq. (10) with $a_{2}=2.75, a_{3}=5.79$ are compared with the case of uniform source strength $\left(a_{2}=a_{3}=1\right)$. The values of $a_{2}$ and $a_{3}$ are obtained from Fig. 6 at $M_{j}=1.4$, relative to the first shock-cell strength of 3.5 . For comparison purposes the directivity data of Norum [12] for a choked nozzle at $M_{j}=1.49$ are included. The frequencies of the fundamental and the second harmonic in this data are respectively $19 \mathrm{~Hz}$ and $38 \mathrm{~Hz}$.

For the fundamental (Fig. 10a), the directivity pattern from the model displays three lobes. One lobe, namely the principal lobe, radiates upstream and forms part of the feedback loop. The next dominant lobe radiates downstream at a relatively small angle from the downstream flow direction. The third lobe is the weakest one, which radiates in a direction normal to the jet axis. The directivity of the fundamental displaying the predominant lobe in the upstream direction is consistent with the well-known trends of the screech data [12]. The relatively rapid decline in SPL data at about $20 \mathrm{deg}$ and $160 \mathrm{deg}$ is believed to be a consequence of possible refraction effects, which are important for high temperature and high speed jets but are outside the scope of the present theory. The data for the fundamental however do not display the weakest lobe (normal to the jet axis), as indicated by the theory. It is evident from the present model that the effect of variable strength relative to uniform strength is displayed only in the weakest lobe and is not significant in the primary lobe directed upstream. 
Fig. 10b for the directivity of the second harmonic suggests that the peak radiation due to screech is in a direction normal to the jet axis - an established result that is in concurrence with the available measurements, such as those of Norum [12]. Again, the variation of strength has some influence on the predicted directionality of the second harmonic in the three subordinate lobes only and does not alter appreciably the directivity of the primary lobe directed normal to the jet axis. The theory considerably underpredicts the upstream lobe levels for the harmonic. As in the fundamental, the directivity data for the harmonic show possible refraction effects at about $20 \mathrm{deg}$ and $160 \mathrm{deg}$. Larger number of sources may in general improve the accuracy of the predictions for the directivity- both the fundamental and the second harmonic.

The proposed method is applicable also to a forward flight stream surrounding the jet by appropriately modifying Eq. (2a) and (2b), and with a proper choice for the value of $M_{c}$ in Eq. (10). Measurements by Krothapalli et al. [22] with a freestream Mach number from 0 to 0.32 with an underexpanded heated supersonic jet (nozzle pressure ratios up to 4.5 ) reveal that the screech intensity is unaltered by the forward flight. Cold jet data by Norum and Shearin [48] indicate the existence of intense screech tones in simulated forward flight up to Mach 0.41 .

\section{Conclusions}

Quantitative estimates for the excess screech tone amplitude over a range of fully expanded jet Mach number, as derived from the present model, seem to satisfactorily agree with the experimental data for underexpanded supersonic jets. The predicted streamwise amplification of the acoustic source strength is also found to be consistent with the available measurements, especially at low Mach numbers. This favorable comparison between the theory and the measurements suggests that the proposed physical model for the amplification of downstreampropagating disturbances of finite amplitude based on shock-acoustic wave interaction theory 
represents a plausible mechanism of screech in the feedback cycle. The results also indicate that the directivity of screech due to variable source strength of the discrete monopole source in each shock-cell does not appreciably differ from that based on uniform source strength insofar as the principal lobes are concerned. The proposed hypothesis for the determination of screech amplitude appears to hold promise in our effort to refine the jet screech modeling.

\section{Acknowledgment}

The author would like to thank the reviewers for their valuable suggestions and criticism that improved the manuscript. 


\section{References}

[1] Lighthill, M.J., "On sound generated aerodynamically, I. General theory," Proceedings of the Royal Society A, Vol. 211, 1954, pp. 564-587.

[2] Lighthill, M.J., "On sound generated aerodynamically, II. Turbulence as a source of sound," Proceedings of the Royal Society A, Vol. 222, 1952, pp. 1-32.

[3] Ffowcs Williams, J.E., The noise from turbulence convected at high speed, Proceedings of the Royal Society A, Vol. 255, 1963, p. 469.

[4] Kandula, M., "An experimental and numerical study of sound propagation from a supersonic jet passing through a rigid-walled duct with a J-deflector," International Journal of Acoustics and Vibration, Vol. 11, 2006, pp. 125-131.

[5] Kandula, M. "Near-field acoustics of clustered rocket engines," accepted for publication in the Journal of Sound and Vibration, 2007.

[6] Kandula, M., "A nonlinear shock-refracted acoustic wave model for the prediction of screech amplitude in underexpanded supersonic jets.” AIAA Paper 2006-2674, 2006.

[7] Powell, A., "On the mechanism of choked jet noise," Proceedings of the Physical Society, London B, Vol. 4, 1953, pp. 1039-1056.

[8] Powell, A., "On the noise emanating form a two-dimensional jet above the critical pressure," The Aeronautical Quarterly," Vol. 4, 1953, pp.103-122.

[9] Powell, A., "The noise of choked jets," Journal of the Acoustical Society of America, Vol. 25,1953 , pp. $385-389$.

[10] Kaji, S. \& Nishijima, N., "Pressure field around a rectangular supersonic jet in screech," AIAA Journal, Vol. 34, 1996, pp.1990-1996.

[11] Seiner, J.M., “Advances in high speed jet aeroacoustics,” AIAA Paper 84-2275, 1984. 
[12] Norum, T. D., "Screech suppression in supersonic jets," AIAA Journal, Vol. 21, 1983, pp. 235-240.

[13] Fisher, M. J. \& Morfey, C. L., "Jet Noise," In AGARD Lecture Series, Aerodynamic Noise, No. $80,1976$.

[14] Tam, C. K. W., Seiner, J. M. and Yu, J. C., "Proposed relationship between broadband shock associated noise and screech tones." Journal of Sound and Vibration, Vol. 110, 1986, pp. 309-321.

[15] Massey, K. C., Ahuja, K. K., Jones, III, R. R and Tam, C. K. W., "Screech tones of supersonic heated free jets, AIAA Paper 93-0141, 1993.

[16] Harper-Bourne, M. \& Fisher, M. J., "The noise from shock waves in supersonic jets," In Proc. AGARD Conference on Noise Mechanisms, AGARD-CP-131, paper No. 11, Brussels, Belgium, 1973.

[17] Tam, C. K. W., Stochastic model theory of broadband shock associated noise from supersonic jets," Journal of Sound and Vibration, Vol. 116, 1987, pp. 265-302.

[18] Lui, C., and Lele, S. K., "A numerical study of shock-associated noise," AIAA Paper 20022530, 2002.

[19] Panda, J., Raman, G., and Zaman, K., "Underexpanded screeching jets from circular, rectangular and elliptic nozzles," AIAA Paper 97-1623, 1997.

[20] Panda, J., "Shock oscillation in underexpanded jets," Journal of Fluid Mechanics, Vol. 363, 1998, pp.173-198.

[21] Panda, J., "An experimental investigation of screech noise generation," Journal of Fluid Mechanics, Vol. 378, 1999, pp. 71-96. 
[22] Krothapalli, A., Hsia, Y., Baganoff, D., and Karamcheti, K., "The role of screech tones in mixing of underexpanded rectangular jet," Journal of Sound and Vibration, Vol. 116, 1986, pp. 119-143.

[23] Petitjean, B. P., Morris, P. J., and McLaughlin, D. K., "On the nonlinear propagation of shock-associated noise," AIAA Paper 2005-2930, 2005.

[24] Shen, H. and Tam, C. K. W., "Three-dimensional numerical simulation of the jet screech phenomenon," AIAA Journal, Vol. 40, 2002, pp. 33-41.

[25] Manning, T. A. and Lele, S. K., "Numerical simulations of shock vortex interactions in supersonic jet screech," AIAA-98-0282, 1998.

[26] Manning, T. A., and Lele, S. K., "A numerical investigation of sound generation in supersonic jet screech," AIAA Paper 2000-2081, 2000.

[27] Loh, C. Y., Himansu, A., and Hultgren, L. S., "A 3-D CE/SE Navier-Stokes solver with unstructured hexahedral grid for computation of near field jet screech noise," AIAA Paper 2003-3207, 2003.

[28] Li, X. D. and Gao, J. H., "Numerical simulation of three-dimensional supersonic jet screech tones," AIAA Paper 2005-2882, 2005.

[29] Berland, J., Bogey, C., and Bailly, C., "Large eddy simulation of screech tone generated in a planar underexpanded jet,"AIAA-2006-2496, 2006.

[30] Glaznev, V. N., Some features of the propagation of the discrete tone perturbation in a free supersonic jet. Fluid Mechanics Soviet Research, Vol. 2, 1963, pp. 76-79. 
[31] Sedel'nikov, T. Kh., "The discrete component of the frequency spectrum of the noise of a free supersonic jet," In Physics of Aerodynamic Noise (ed. A. V. Rimskiy-Korsakov), Nauka, Moscow, 1967.

[32] Raman, G., "Advances in understanding supersonic jet screech: Review and Perspective," Progress in Aerospace Sciences, Vol. 34, 1998, pp. 45-106.

[33] Raman, G., "Supersonic jet screech: Half-century from Powell to the present," Journal of Sound and Vibration, Vol. 225, 1999, pp. 543-571.

[34] McKenzie, J. F. and Westphal, K. O., "Interaction of linear waves with oblique shock waves," Physics of Fluids," Vol. 11, 1968, 2350-2362.

[35] Kontorovich, V. M., Reflection and refraction of sound by shock waves," Soviet Physics Acoustics, Vol. 5, 1960, pp. 320-330.

[36] Blokhintsev, D. I., "A moving sound pickup," Doklady Akad, Nauk SSSR, Vol. 47, 1945, pp. 22-25.

[37] Burgers, J. M., On the transmission of sound waves through a shock wave. Proc. Ned. Acad. Wet., Vol. 49, 1946, pp. 273-281.

[38] Shapiro, A. H., The Dynamics and Thermodynamics of Compressible Fluid Flow, Vol. 1, Wiley, New York, 1953.

[39] Zong, T.A., Hussain, M.Y., and Bushnell, D.M., "Numerical computation of turbulence amplification in shock-wave interactions," AIAA Journal, Vol. 22, 1984, pp. 13-21.

[40] Massey, K. C. and Ahuja, K. K., "Screech frequency prediction in light of mode detection and convection speed measurements for heated jets," AIAA Paper 97-1625, 1997.

[41] Rayleigh, Lord, "On point-, line- and plane-sources of sound," Proceedings of London Mathematical Society, Vol. 19, 1998, p. 504. 
[42] Harper-Bourne, M. On Modeling the near-field noise of the high-speed jet exhausts of combat aircraft, AIAA Paper 2002-2424, 2002.

[43] Raman, G. and Rice, E.J., "Instability modes excited by natural screech tones in a supersonic reçtangular jet," Physics of Fluids, Vol. 6, 1994, pp.3994-4008.

[44] Raman, G., "Cessation of screech in underexpanded jets," Journal of Fluid Mechanics, Vol. 336, 1997, pp. 69-90.

[45] Ponton, M.K. and Seiner, J.M., "The effects of nozzle lip thickness on plume resonance. Journal of Sound and Vibration," Vol. 154, 1992, pp. 531-549.

[46] Seto, K., Khan, M.T.I. and Teramoto, K., "The reduction of jet noise with spherical reflector and evaluation of its performance compared to a flat reflector," Int. J. Acoustics and Vibration, Vol. 11, 2006, pp.187-195.

[47] Suzuki, T., and Lele, S.K., Shock leakage through an unsteady vortex-laden mixing layer: application to jet screech, Journal of Fluid Mechanics, Vol. 490, 2003, pp. 139-167.

[48] Norum, T. and Shearin, J.G., "Shock structure and noise of supersonic jets in simulated flight to Mach 0.4," NASA TP 2785, 1988. 


\section{Captions to Figures}

Fig. 1 A typical narrowband farfield shock noise spectrum (adapted from Seiner [11].

Fig. 2 Schematic of the feedback loop in supersonic jet screech according to Powell [1-3].

Fig. 3 Idealized distribution of acoustic sources in an underexpanded jet.

Fig. 4 Interaction of an acoustic wave with a stationary shock wave (McKenzie \& Westphal [34].

Fig. 5 Acoustic pressure amplification as a function of upstream Mach number.

Fig. 6a Streamwise amplification of acoustic source strength from present theory for $\beta_{1}=90 \mathrm{deg}$.

Fig. $6 \mathrm{~b}$ Streamwise amplification of acoustic source strength from present theory for $\beta_{1}=60 \mathrm{deg}$.

Fig. 6c Comparison of predicted streamwise amplification of acoustic source strength with test data.

Fig. 7a Streamwise amplification of acoustic source strength from the data of Kaji \& Nishijima [10] for $M_{j}=1.64$.

Fig. 7b Streamwise amplification of acoustic source strength from the data of Panda [19].

Fig. 7c Streamwise amplification of acoustic source strength from the numerical simulation of Manning \& Lele [26].

Fig. 8 Comparison of the dependence of excess screech amplitude on Mach number.

Fig. 9 Dependence of measured screech amplitude on Mach number, from data of Panda [19].

Fig. 10a Directivity of the screech fundamental.

Fig. 10b Directivity of screech second harmonic. 


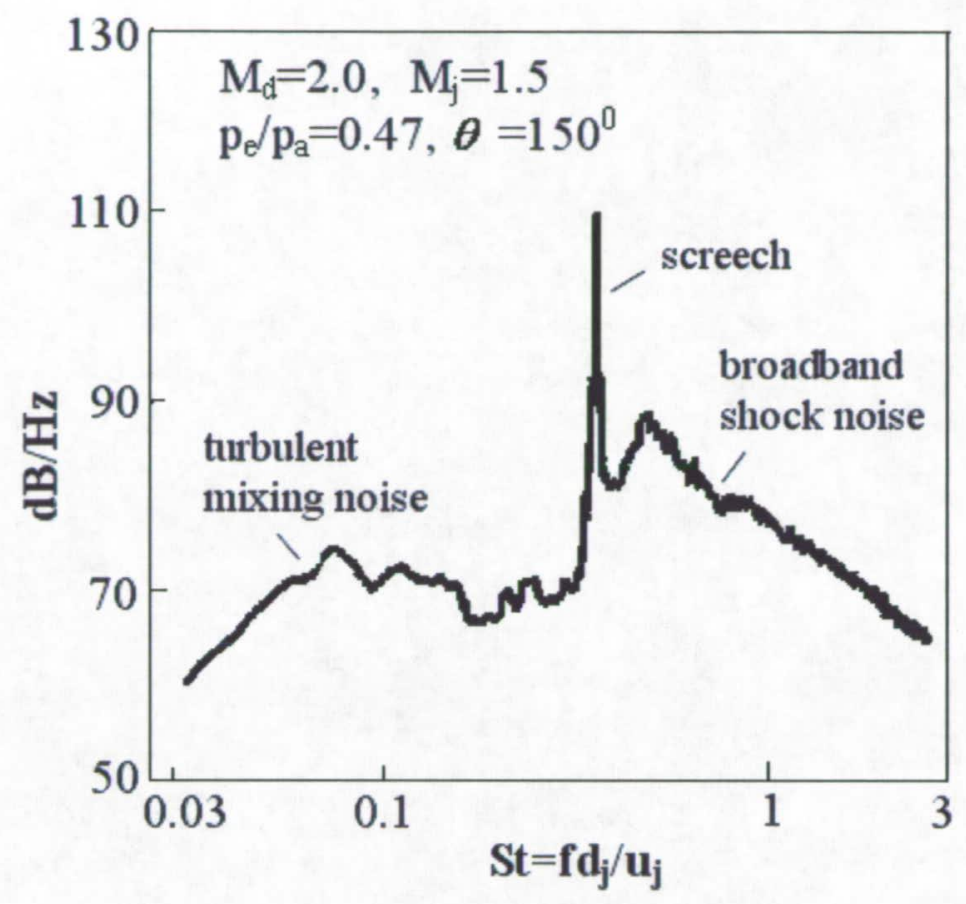

Fig. 1 A typical narrowband farfield shock noise spectrum (adapted from Seiner [11]. 


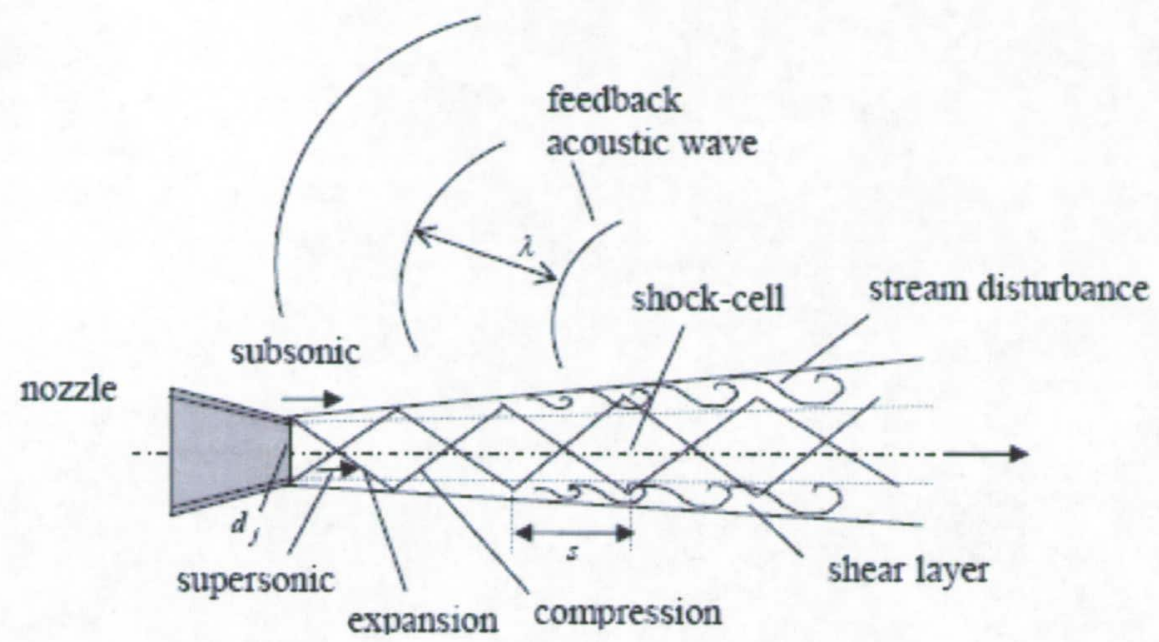

Fig. 2 Schematic of the feedback loop in supersonic jet screech according to Powell [1-3].

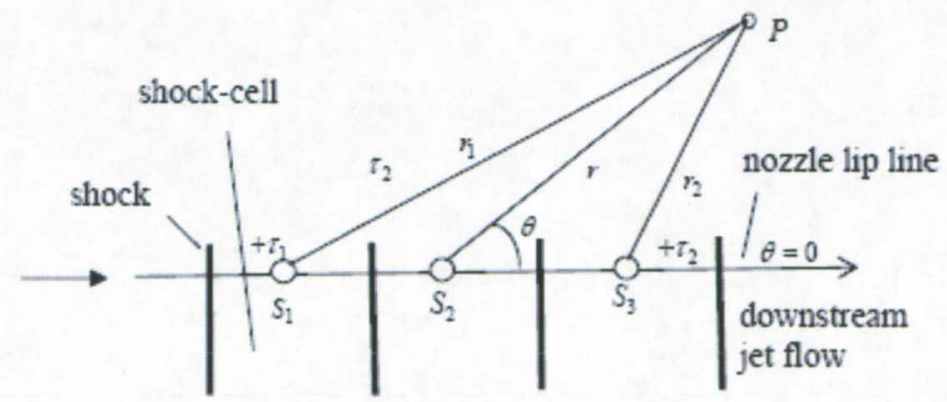

Fig. 3 Idealized distribution of acoustic sources in an underexpanded jet. 


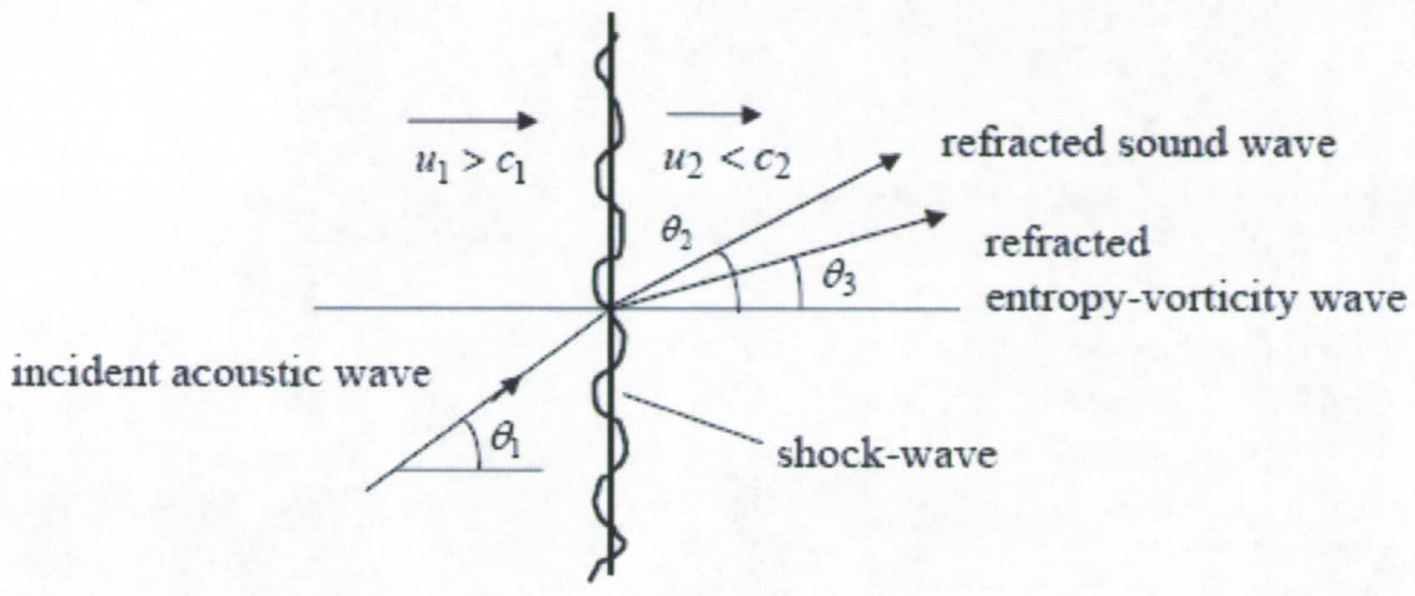

Fig. 4 Interaction of an acoustic wave with a stationary shock wave (McKenzie and Westphal [34].

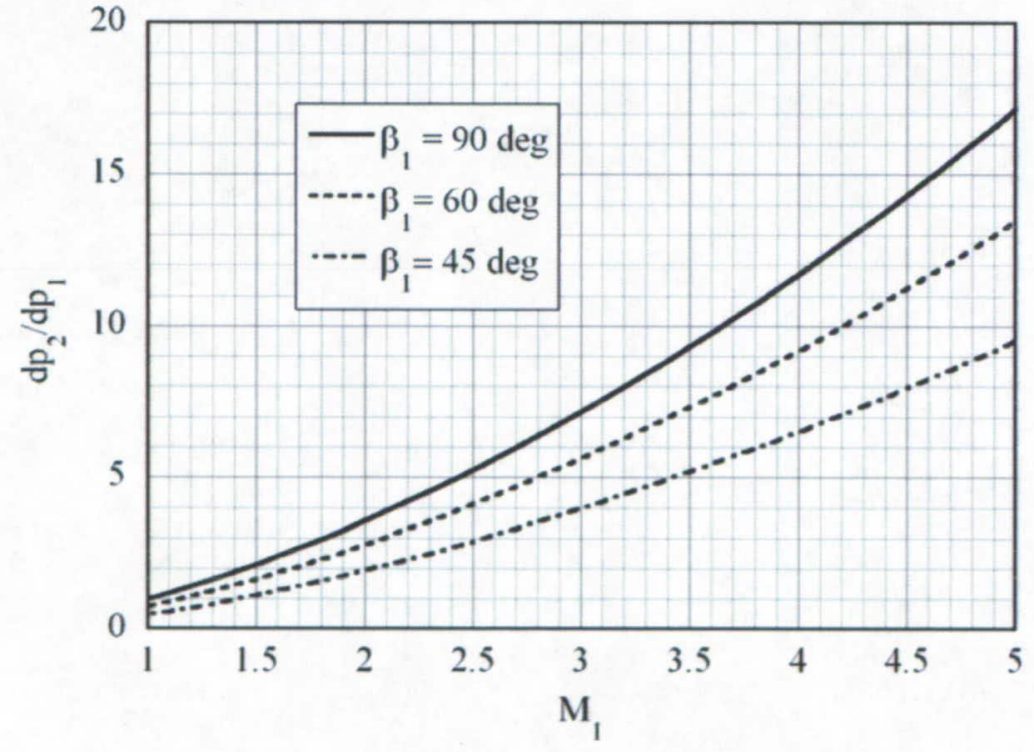

Fig. 5 Acoustic pressure amplification as a function of upstream Mach number. 


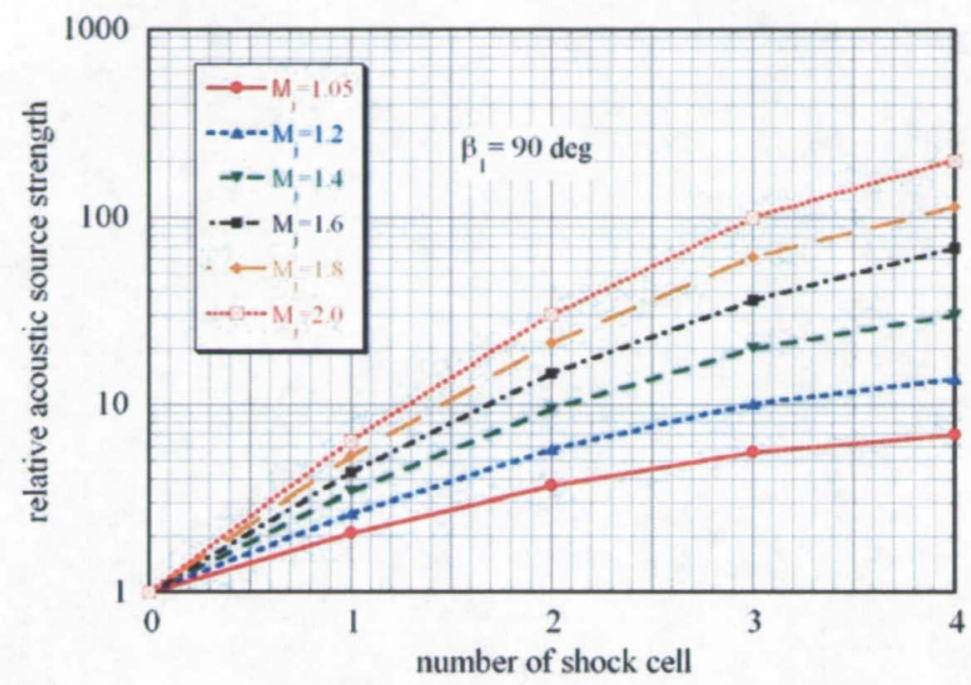

Fig. 6a Streamwise amplification of acoustic-source strength from present theory for $\beta_{1}=90$ deg.

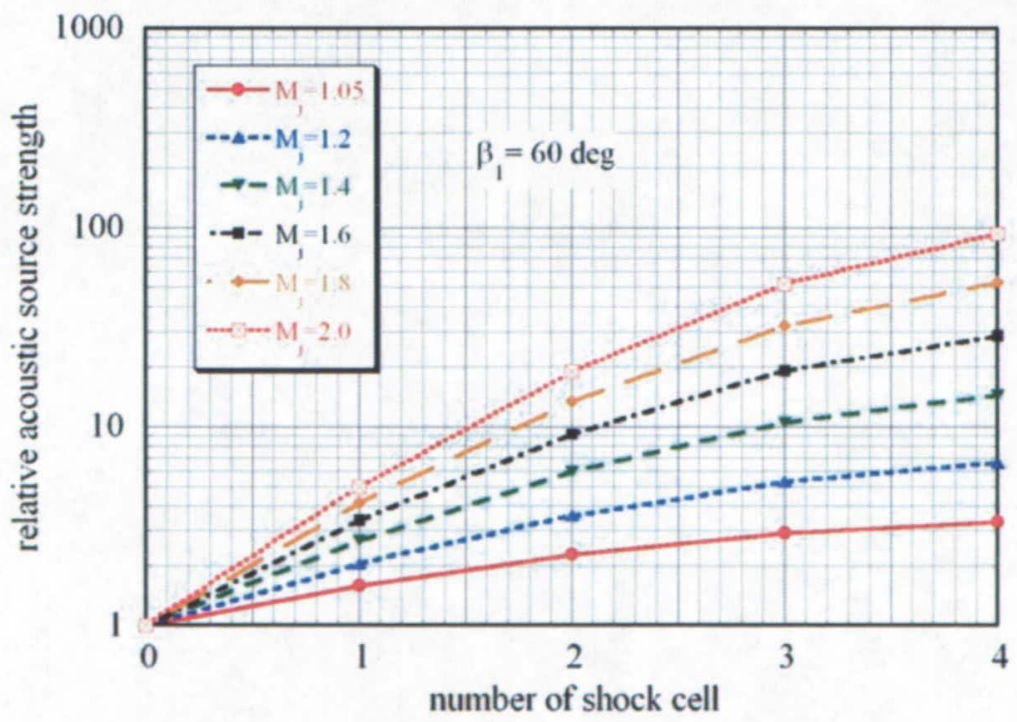

Fig. 6b Streamwise amplification of acoustic-source strength from present theory for $\beta_{1}=60 \mathrm{deg}$. 


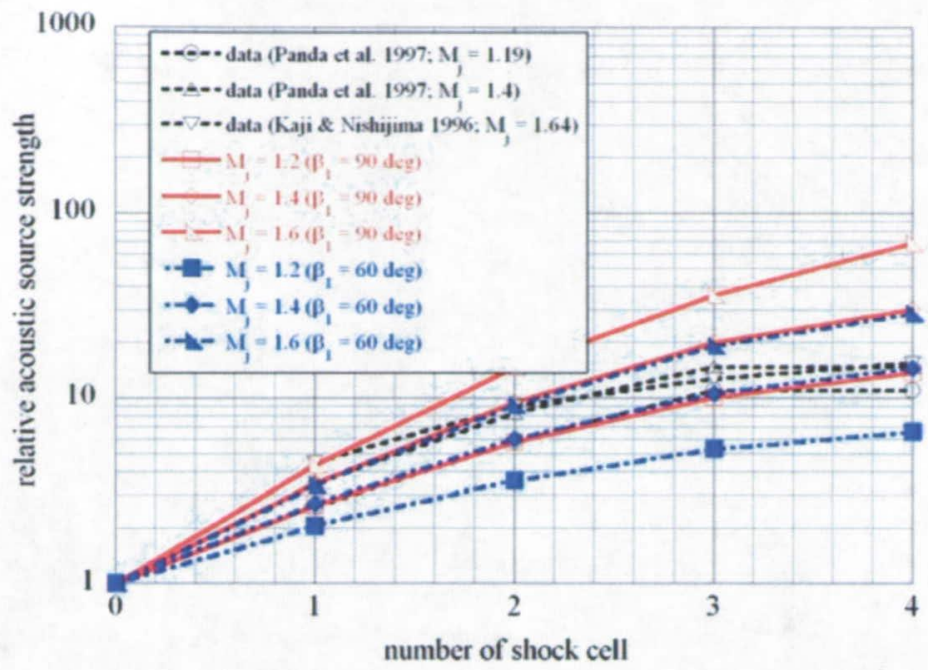

Fig. 6c Comparison of predicted streamwise amplification of acoustic source strength with test data.

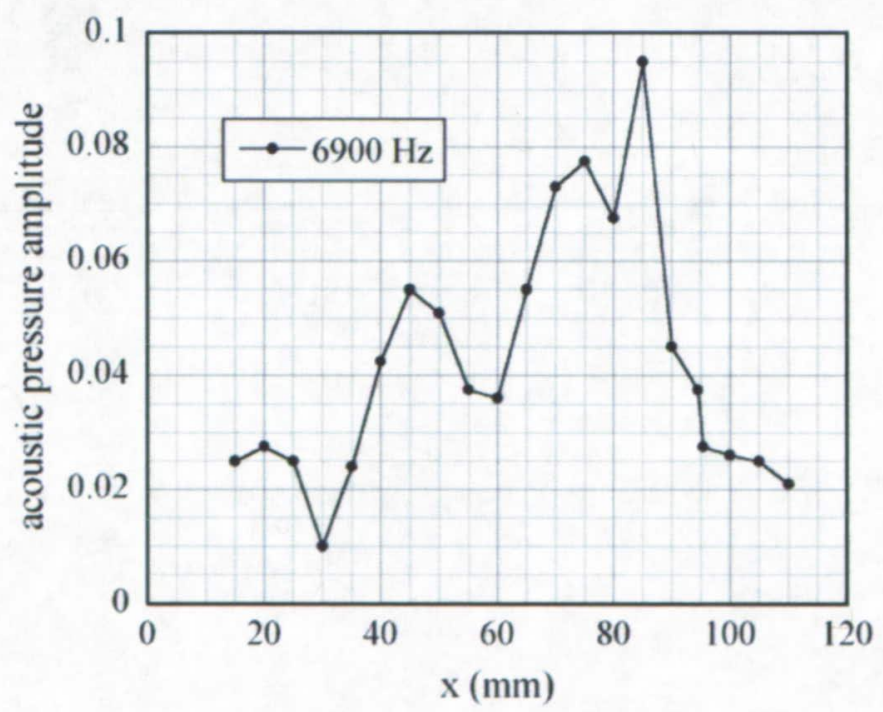

FIG. 7a Streamwise amplification of acoustic source strength from the data of Kaji and Nishijima for $M_{j}=1.64$. 


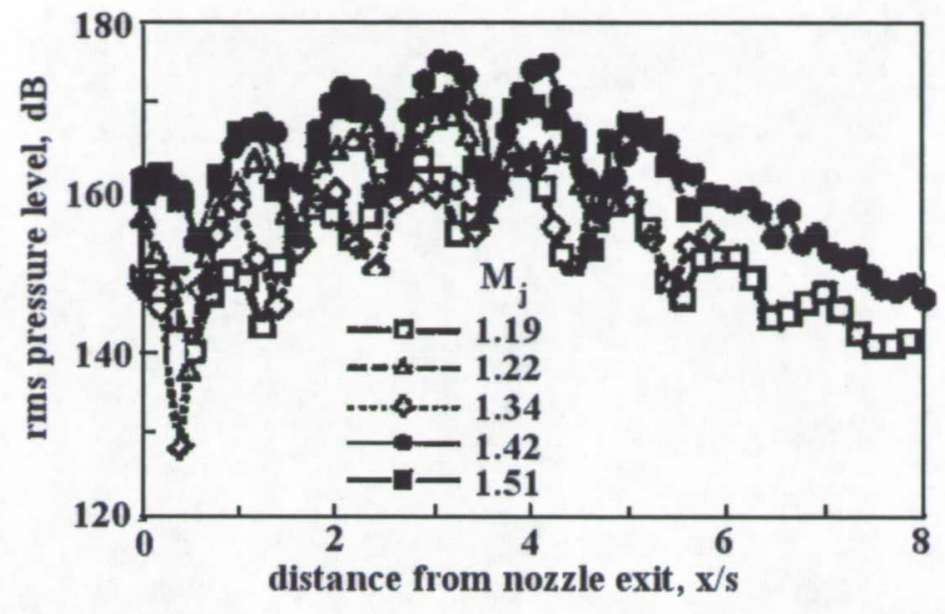

Fig. 7b Streamwise amplification of acoustic-source strength from the data of Panda [19].

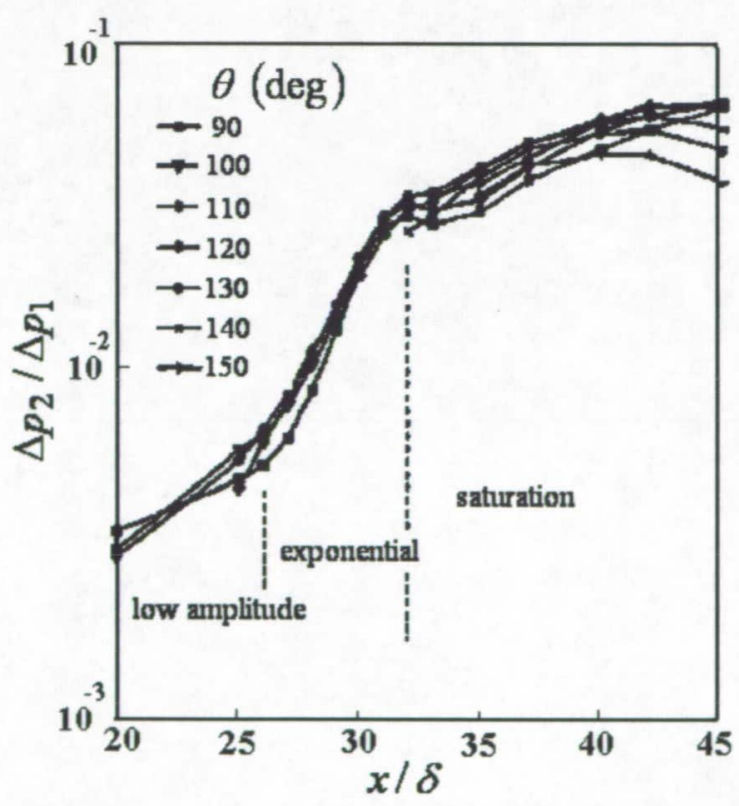

Fig. 7c Streamwise amplification of acoustic-source strength from the numerical simulation of Manning and Lele [26]. 


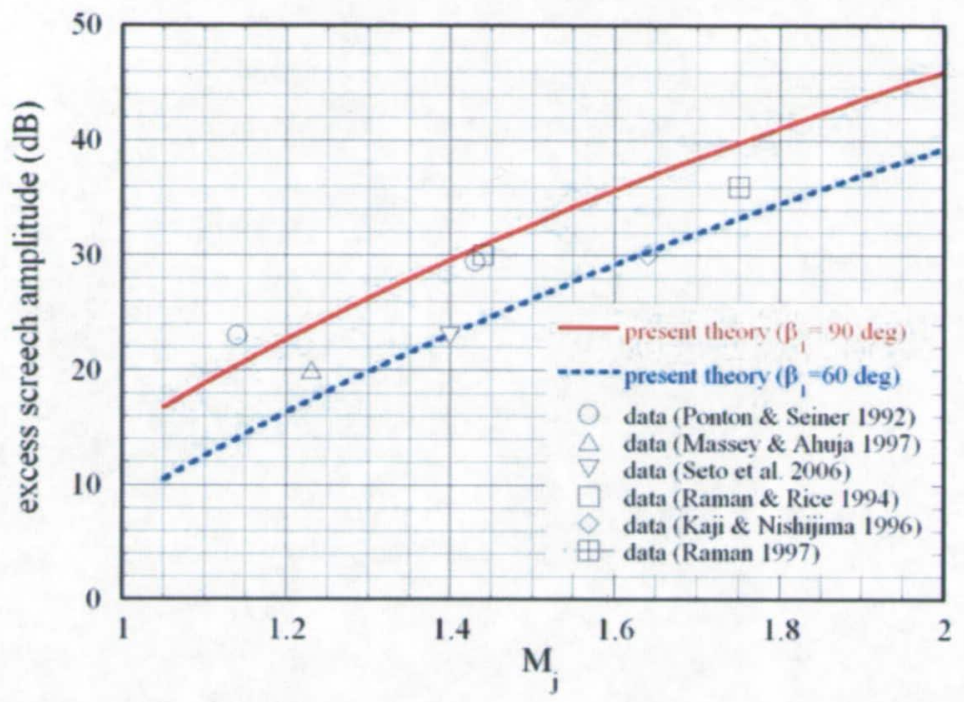

Fig. 8. Comparison of the dependence of excess screech amplitude on Mach Number.

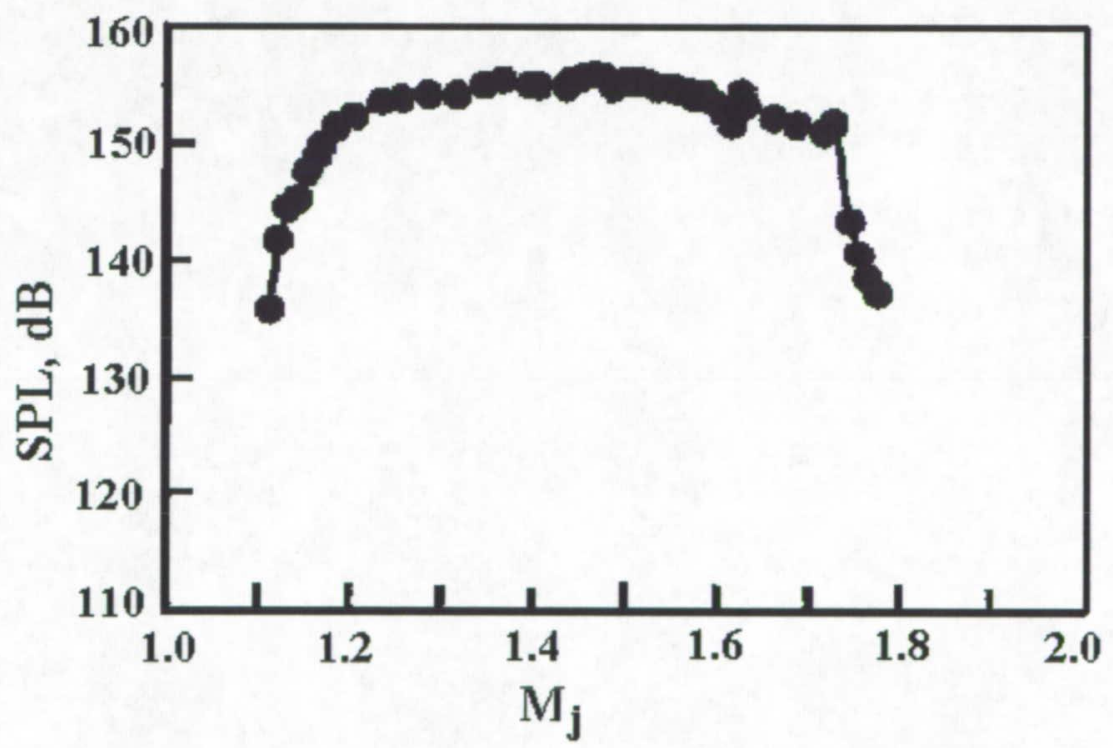

Fig. 9 Dependence of measured screech amplitude on Mach number, from data of Panda [19]. 


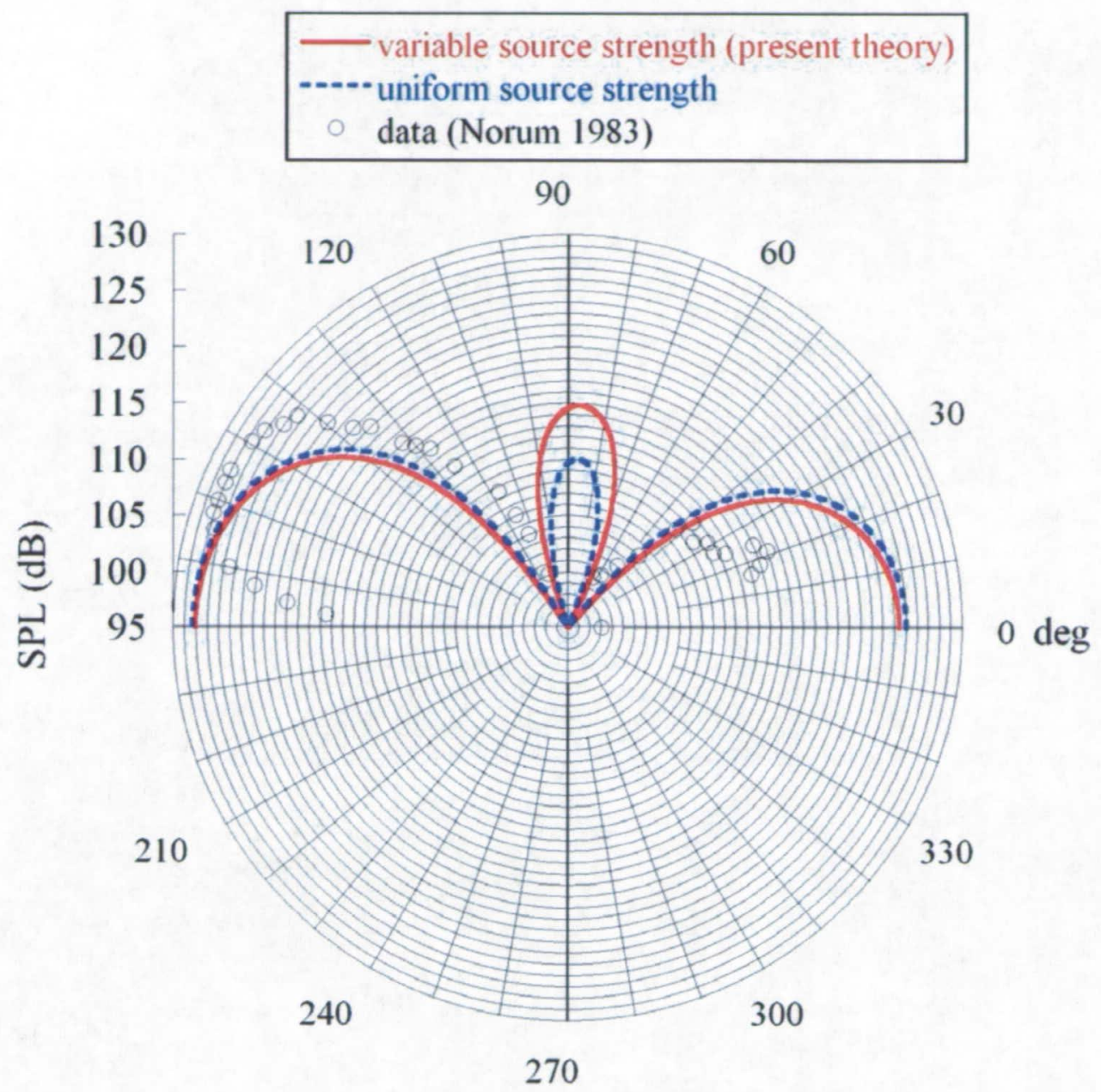

Fig. 10a Directivity of the screech fundamental. 


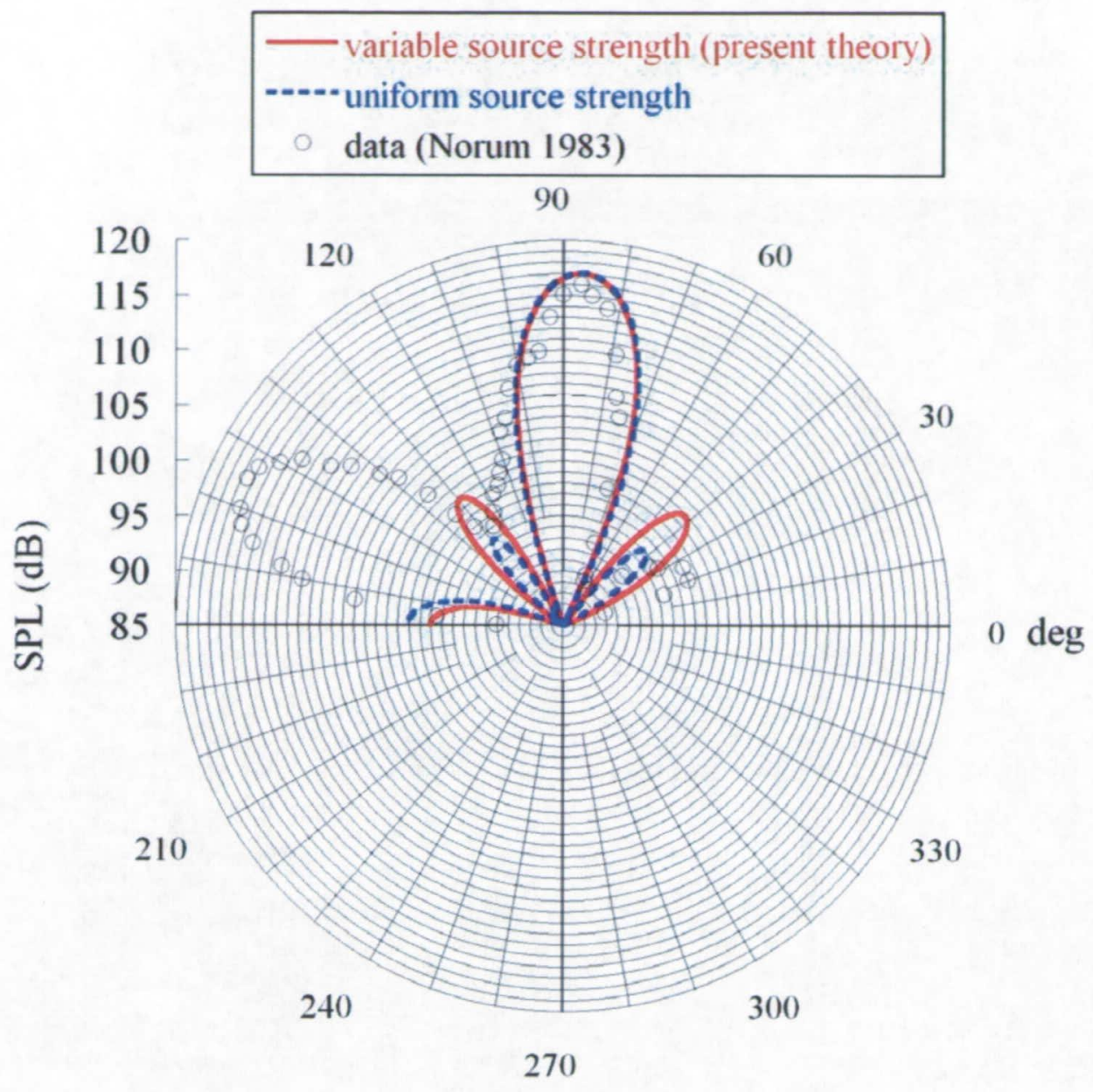

Fig. 10b Directivity of the screech second harmonic. 


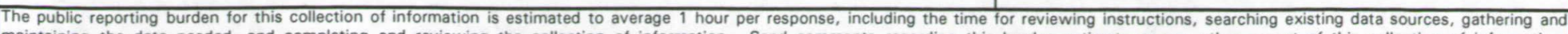

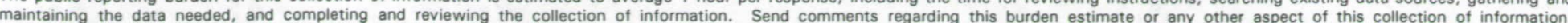

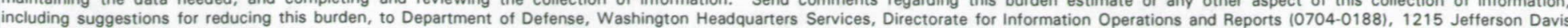

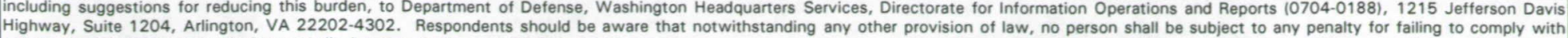
a collection of information if it does not display a currently valid $O M B$ control number.

PLEASE DO NOT RETURN YOUR FORM TO THE ABOVE ADDRESS. RETURN COMPLETED FORM TO

\begin{tabular}{l|l} 
1. REPORT DATE (DD-MM-YYYY) & $\begin{array}{l}\text { 2. REPORT TYPE } \\
\text { journal article }\end{array}$ \\
\hline
\end{tabular}

4. TITLE AND SUBTITLE

journal article

A Shock-refracted Acoustic Wave Model for Screech Amplitude in Supersonic Jets

3. DATES COVERED (From - To)

5a. CONTRACT NUMBER

NAS10-03006

5b. GRANT NUMBER

5c. PROGRAM ELEMENT NUMBER

6. AUTHOR(S)

5d. PROJECT NUMBER

Max Kandula

5e. TASK NUMBER

5f. WORK UNIT NUMBER

8. PERFORMING ORGANIZATION REPORT NUMBER

Sierra Lobo, Inc.

ASRC-3

Kennedy space Center, FL 32899

9. SPONSORING/MONITORING AGENCY NAME(S) AND ADDRESS(S)

National Aeronautics and Space Administration

Engineering Directorate (NE)

Kennedy Space Center, FL 32899

10. SPONSOR/MONITOR'S ACRONYM(S)

NASA KSC

11. SPONSOR/MONITOR'S REPORT NUMBERS(S)

12. DISTRIBUTION AVAILABILITY STATEMENT

\section{SUPPLEMENTARY NOTES}

\section{ABSTRACT}

A physical model is proposed for the estimation of the screech amplitude in underexpanded supersonic jets. The model is based on the hypothesis that the interaction of a plane acoustic wave with stationary shock waves provides amplification of the transmitted acoustic wave upon traversing the shock. Powell's discrete source model for screech incorporating a stationary array of acoutic monopoles is extended to accommodate variable source strength. The proposed model reveals that the acoustic sources are of increasing strength with downstream distance. It is shown that the screech amplitude increases with the fully expanded jet Mach number.

\section{SUBJECT TERMS}

Shock-refracted Acoustic Wave Model, screech, screech amplitude, supersonic jets, shock waves, acoustic waves

16. SECURITY CLASSIFICATION OF: \begin{tabular}{|l|l|}
\hline a. REPORT & b. ABSTRACT \\
\hline
\end{tabular}

\begin{tabular}{|l|l|}
\hline b. ABSTRACT & c. THIS PAGE \\
\end{tabular}

AUTHORIZED FOR LOCAL REPRODUCTION

Previous edition is not usable
17. LIMITATION OF ABSTRACT

\begin{tabular}{|l|l}
$\begin{array}{c}\text { 18. NUMBER } \\
\text { OF } \\
\text { PAGES }\end{array}$ & 19a. NAME OF RESPONSIBLE PERSON \\
\cline { 2 - 3 } & Max Kandula
\end{tabular}

19b. TELEPHONE NUMBER (include area code)
(321) $867-4456$

STANDARD FORM 298 (Rev, 8-98)

Prescribed by ANSI Std. 239.18 